\title{
Perceptions of use of a case-based, integrated national electronic public health surveillance system in Jordan
}

Rania Khorma ', Fatima A. Hammad', Samar Samouh ', Refqi I. Mahmoud ', Meyassar Zindah ', Sami A. Sheikhali ', Ayoub Assayideh ', Bashir Al Qaseer ${ }^{7}$, Gunnar Rø ${ }^{2,3}$ and John Haskew ${ }^{2}$

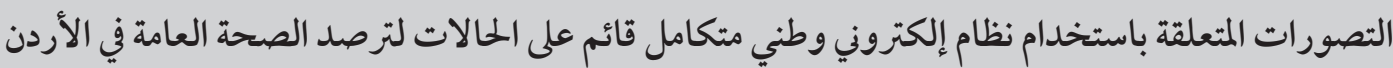

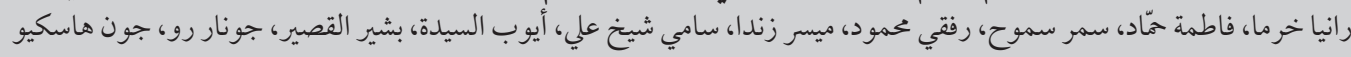

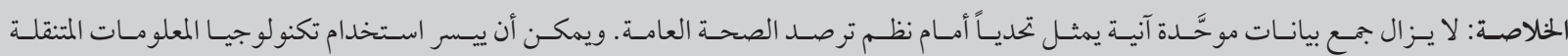

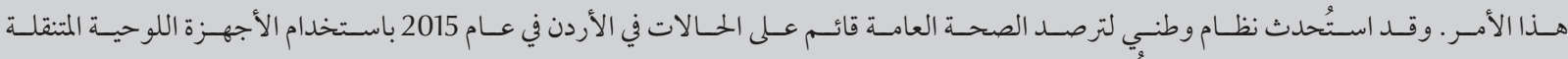

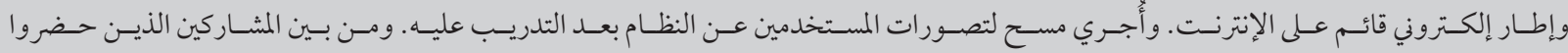

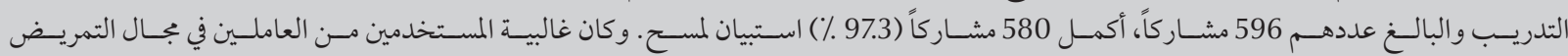

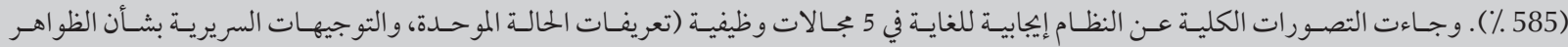

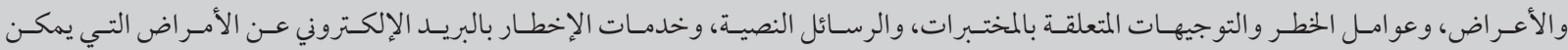

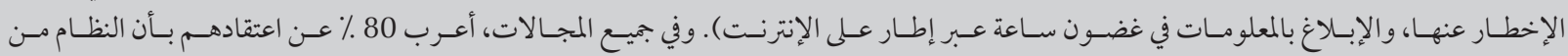

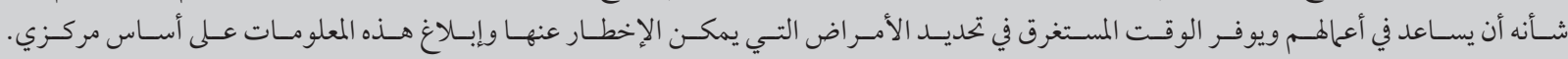

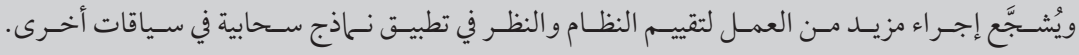

ABSTRACT Collection of real-time, standardized data remains a challenge for public health surveillance systems. The use of mobile information technology may facilitate this. A national case-based public health surveillance system was introduced in Jordan in 2015 using mobile tablets and an online framework. After training on the system, users were surveyed about their perceptions of it. Of 596 participants attending the training, 580 (97.3\%) completed the survey. The majority of users were nurses (58.5\%). Overall perceptions of the system were highly positive across 5 areas of functionality (standardized case definitions, clinical guidance on signs and symptoms, risk factors and laboratory guidance, SMS and Email alerts for notifiable diseases, one-hour reporting of information via an online framework). In all areas, over $80 \%$ of participants thought the system would help their work and would save time in identifying notifiable diseases and reporting this information centrally. Further work is encouraged to evaluate the system and consider the application of cloud-based models in other settings.

Perceptions de l'utilisation d'un système national de surveillance de santé publique intégré et électronique fondé sur les cas en Jordanie

RÉSUMÉ La collecte, en temps réel, de données normalisées constitue un défi pour les systèmes de surveillance de santé publique. L'utilisation des technologies de l'information mobiles peut faciliter cette tâche. En 2015, un système national de surveillance de santé publique fondé sur les cas et utilisant des tablettes et une plate-forme en ligne a été introduit en Jordanie. Suite à une formation sur l'utilisation du système, un sondage a été effectué auprès des utilisateurs pour connaître leurs perceptions concernant ce système. Sur 596 participants à la formation, 580 (97,3\%) ont complété le sondage. La majorité des utilisateurs étaient des personnels infirmiers (58,5\%). Les perceptions globales du système avaient tendance à être très positives dans cinq domaines de fonctionnalité, qui sont les suivants : les définitions de cas normalisées, les directives cliniques sur les signes et les symptômes, les facteurs de risque et les directives concernant les laboratoires, les SMS et les alertes par courriel des maladies à déclaration obligatoire, et la notification des informations sur une plate-forme en ligne dans un délai d'une heure. Dans tous les domaines, plus de $80 \%$ des participants considéraient que le système leur servirait dans leur travail et leur ferait gagner du temps dans l'identification des maladies à déclaration obligatoire et la notification de cette information au niveau central. Il conviendrait d'encourager davantage l'évaluation du système et d'envisager l'application de modèles basés sur un cloud dans d'autres établissements.

'Ministry of Health, Amman, Jordan. ${ }^{2}$ World Health Organization, Jordan Country Office, Amman, Jordan (Correspondence to: John Haskew: john.haskew@gmail.com). ${ }^{3}$ Department of Physics, University of Durham, Durham, United Kingdom.

Received: 31/07/16; accepted: 18/12/16 


\section{Introduction}

Public health surveillance is the ongoing, systematic assessment of the health of a community, based on the collection, interpretation and use of health data and information (1). Surveillance programmes often rely on multiple layers of reporting structure from the facility to central level, which can result in delays in data collection, analysis and reporting, particularly in insecure and inaccessible areas (2). Adoption of standardized case definitions and guidelines for accurate diagnosis also remains a challenge for public health surveillance systems $(3,4)$.

Technological innovations within public health surveillance, including the use of mobile information technology, may help enable standardized data to be collected in real-time, and several advantages have been reported that could help to inform and improve decision-making for surveillance $(5,6)$. Electronic data collection has been proposed as a solution to many challenges faced by paper-based surveillance and is increasingly being adopted in a number of public health programmes (7-9).

An innovative national programme of public health surveillance is being implemented across Jordan, in partnership with the Ministry of Health and the World Health Organization, to monitor the epidemiology of priority public health diseases, conditions and events (10). The programme utilizes mobile information technology to enable reporting of information in real-time from primary and secondary care facilities across the country. Mobile tablets are used by health workers during the consultation with the patient to provide case-based reporting of disease which is coded in a structured manner according to the International Classification of Diseases (ICD-10) (11).

The public health surveillance system was approved for use in Jordan by the Ministry of Health and adheres to national surveillance standards and case definitions. It was built using free, open source software and builds on common platforms and previous work. The system uses a cloud-based model, meaning the server and data are hosted centrally by the Ministry of Health, which removes the need for local clinic infrastructure and enhances data access and sharing at different levels of the health system. A total of 55 communicable diseases, 7 noncommunicable diseases and 12 mental health conditions are currently included in the surveillance system (12).

National scale-up and implementation of the public health surveillance system in Jordan took place in a phased manner between April and September 2015, following pilot project implementation between May and December 2014 (13). A total of 297 primary and secondary care facilities are included in the system, using a total of 439 mobile tablets, across all 14 governorates of the country. All facilities received a half-day training on the use of mobile tablets and appropriate techniques for case-based reporting.

This paper reports on the perceptions of the users about the usefulness of various aspects of the system to help their work.

\section{Methods}

\section{User survey}

A survey of users of the public health surveillance system was completed immediately following each training to evaluate perceptions of use of the system by health care workers. A total of 596 participants attended training during the national scale-up and all were invited to participate in the survey. A total of 580 (97.3\%) participants completed the survey.

\section{Survey questions}

Two domains of questions were chosen for inclusion within the survey following working group discussion with users as well as with Ministry of Health directorates of communicable disease, noncommunicable disease and information technology. The domains covered the principle utilities of the system, namely clinical decision support (providing a standardized case definition for each disease, clinical guidance on signs and symptoms, risk factors and laboratory guidance) and improved reporting and response (SMS and Email alerts for notifiable diseases, reporting of information within 1 hour via an online framework).

\section{Data collection}

The survey was available in Arabic and English, designed in extended markup language (XML) and uploaded to tablets. Each form was programmed for the Open Data Kit (ODK) (14) application and skip logic algorithms were used. The survey was self-administered by the user on the tablet following each training. Data were sent to a central server where they were subsequently downloaded for analysis.

\section{Statistical analysis}

Only anonymized survey data were used in the study analysis. All data were analysed using STATA, version 13.1.

\section{Ethics statement}

This was an emergency public health programme designed to increase monitoring in key public health diseases, conditions and events in Jordan, in line with goals set by the Ministry of Health in Jordan. It thus did not require institutional review board and ethical approvals. All data were anonymized prior to analysis. The study was approved by the Director of Primary Care and Public Health, Ministry of Health, Jordan.

\section{Results}

A total of 580 users of the public health surveillance system were surveyed 
between 1 April 2015 and 30 April 2016. The majority of users surveyed were nurses and worked across all 14 governorates of the country (Table 1). The remaining users were doctors, data/medical records clerks or other categories (including laboratory technicians, administrative assistants and facility managers). The largest proportion of respondents worked in comprehensive care facilities $(47.8 \%)$, followed by primary health care facilities (36.4\%) and hospitals (9.5\%). The remaining facilities (categorized as other) included influenza sentinel sites, correctional facilities and laboratories (Table 1).

The majority of users across all categories of health worker thought the system would help their work by providing: a standardized case definition for each disease (93.5\%); clinical guidance on signs and symptoms, risk factors and laboratory guidance (89.7\%); SMS and Email alerts for notifiable diseases (80.7\%); and reporting of information within 1 hour via an online framework (90.2\%). The majority of users thought the system would save time in identifying notifiable diseases $(92.6 \%)$ and in reporting this information centrally $(92.9 \%)$ (Table 2).

\section{Discussion}

Acloud-based publichealth surveillance system was implemented in Jordan using mobile information technology and an online framework. User perceptions of the system were very positive in regard to providing: a standardized case definition for each disease; clinical guidance on signs and symptoms, risk factors and laboratory guidance; SMS and Email alerts for notifiable diseases; and reporting of information within 1 hour via an online framework. Users also thought that the system would save time in identifying notifiable diseases and in reporting this information centrally.

\begin{tabular}{|c|c|c|}
\hline Position and location of users & No. $(n=580)$ & $\%$ \\
\hline \multicolumn{3}{|l|}{ Position } \\
\hline Data clerk & 36 & 6.2 \\
\hline Doctor & 97 & 16.7 \\
\hline Nurse & 339 & 58.5 \\
\hline Laboratory technician & 72 & 12.4 \\
\hline Other $^{1}$ & 36 & 6.2 \\
\hline \multicolumn{3}{|l|}{ Facility } \\
\hline Primary health facility & 211 & 36.4 \\
\hline Comprehensive care centre & 277 & 47.8 \\
\hline Hospital & 55 & 9.5 \\
\hline Other $^{2}$ & 37 & 6.3 \\
\hline \multicolumn{3}{|l|}{ Governorate } \\
\hline Ajloun & 35 & 6.0 \\
\hline Amman & 95 & 16.4 \\
\hline Aqaba & 18 & 3.1 \\
\hline Balqa & 28 & 4.8 \\
\hline Irbid & 124 & 21.4 \\
\hline Jerash & 24 & 4.1 \\
\hline Karak & 47 & 8.1 \\
\hline Ma'an & 21 & 3.6 \\
\hline Madaba & 11 & 1.9 \\
\hline Mafraq & 54 & 9.3 \\
\hline Petra & 3 & 0.5 \\
\hline Ramtha & 31 & 5.3 \\
\hline Tafeileh & 34 & 5.9 \\
\hline Zarqa & 55 & 9.5 \\
\hline
\end{tabular}

'Administrative assistants and facility managers.

2Influenza sentinel sites, correctional facilities and laboratories.

No significant differences in user perceptions were recorded according to user type or facility type (data not reported; available on request). It was noted in comments at the end of the survey that some questions were not relevant for particular users, for example those working in noncommunicable diseases and mental health did not use SMS or email alerts (these alerts are generated only for certain notifiable communicable diseases and so are not relevant for noncommunicable disease and mental health focal points). A lower proportion of these respondents therefore reported this domain was relevant to their area of work. More specific questions are recommended for individual user groups in future surveys.

Several methodological limitations of the study are acknowledged. The analyses presented may be subject to respondent bias, which may overestimate the positive user perceptions of the public health surveillance system. In addition, the sample size was not sufficiently powered to provide statistically significant results for individual user groups (doctors, nurses, data clerks).

Further surveys will be conducted after 1 and 2 years to determine if highly positive perceptions of the usefulness of the system are sustained. Further data collection and analysis will also facilitate 


\begin{tabular}{|c|c|c|c|c|c|}
\hline Question & $\begin{array}{l}\text { Data clerk } \\
\text { No. }(\%)\end{array}$ & $\begin{array}{l}\text { Doctor } \\
\text { No. }(\%)\end{array}$ & $\begin{array}{l}\text { Nurse } \\
\text { No. (\%) }\end{array}$ & $\begin{array}{l}\text { Public health } \\
\text { No. (\%) }\end{array}$ & $\begin{array}{c}\text { Total } \\
\text { No. (\%) }\end{array}$ \\
\hline Total surveyed & $36(100)$ & $97(100)$ & $339(95.3)$ & $72(100)$ & $580(100)$ \\
\hline \multicolumn{6}{|c|}{ Do you think the system will help your work by providing: } \\
\hline \multicolumn{6}{|c|}{ A standard case definition for each disease? } \\
\hline No & $1(2.8)$ & $9(9.3)$ & $16(4.7)$ & $7(9.7)$ & $38(6.6)$ \\
\hline Yes & $35(97.2)$ & $88(90.7)$ & $323(95.3)$ & $65(90.3)$ & $542(93.4)$ \\
\hline \multicolumn{6}{|c|}{$\begin{array}{l}\text { Clinical guidance on signs and symptoms, } \\
\text { risk factors and laboratory guidance? }\end{array}$} \\
\hline No & $3(8.3)$ & $8(8.2)$ & $34(10.0)$ & $8(11.1)$ & $60(10.3)$ \\
\hline Yes & $33(91.7)$ & $89(91.8)$ & $305(90.0)$ & $64(89.9)$ & $520(89.7)$ \\
\hline \multicolumn{6}{|c|}{$\begin{array}{l}\text { SMS and Email alerts for notifiable } \\
\text { diseases? }\end{array}$} \\
\hline No & $7(19.4)$ & $17(17.5)$ & $62(18.3)$ & $12(16.7)$ & $112(19.3)$ \\
\hline Yes & $29(80.6)$ & $80(82.5)$ & $277(81.7)$ & $60(83.3)$ & $468(80.7)$ \\
\hline \multicolumn{6}{|c|}{ Information online within 1 hour? } \\
\hline No & $0(0)$ & $8(8.3)$ & $29(8.6)$ & $7(9.7)$ & $57(9.8)$ \\
\hline Yes & $100(100)$ & 89 (91.8) & $310(91.5)$ & $65(90.3)$ & $523(90.2)$ \\
\hline \multicolumn{6}{|c|}{ Do you think the system will save you time in: } \\
\hline \multicolumn{6}{|c|}{ Identifying notifiable diseases? } \\
\hline No & $1(2.8)$ & $11(11.3)$ & $18(5.3)$ & $4(5.6)$ & $43(7.4)$ \\
\hline Yes & $35(97.2)$ & $86(88.7)$ & $321(94.7)$ & $68(94.4)$ & $537(92.6)$ \\
\hline \multicolumn{6}{|c|}{ Reporting notifiable diseases? } \\
\hline No & $1(2.8)$ & $11(11.3)$ & $17(5.0)$ & $3(4.2)$ & $41(7.1)$ \\
\hline Yes & $35(97.2)$ & $86(88.7)$ & $322(95.0)$ & 69 (95.8) & 539 (92.9) \\
\hline
\end{tabular}

a more detailed understanding of the burden of disease among host communities and displaced populations in Jordan. Further work is encouraged to compare the cloudbased public health surveillance model with traditional public health surveillance systems and to consider the application of cloud-based models in other settings. Further studies are also encouraged to consider the implications of case-based reporting within the consultation, including the application of clinical decision support to improve the quality of diagnosis and clinical care. Adoption of mobile technology for public health surveillance in other countries and settings would need to take into account the mobile data network infrastructure as well as local guidelines on data management and security.

\section{Acknowledgements}

We thank all clinic staff, data clerks, nurses and doctors who worked on the project and who contribute to the ongoing surveillance system in Jordan. We also thank the WHO Jordan Country Office for support in the organization and administration of the national training.

\section{Funding: None.}

Competing interests: None declared.

\section{References}

1. Teutsch SM, Churchill RE. Principles and practice of public health surveillance. USA: Oxford University Press; 2000:1.

2. Bernstein $A B$, Sweeney $M H$, Centers for Disease Control and Prevention. Public health surveillance data: legal, policy, ethical, regulatory, and practical issues. MMWR Surveill Summ. 2012 Jul 27;61 Suppl:30-4.

3. Demaio A, Jamieson J, Horn R, de Courten M, Tellier S. Noncommunicable diseases in emergencies: a call to action. PLoS Curr. 2013; Sep 6. Edition 1:5.
4. Alwan A, Maclean DR, Riley LM, d'Espaignet ET, Mathers CD, Stevens GA, et al. Monitoring and surveillance of chronic non-communicable diseases: progress and capacity in highburden countries. Lancet. 2010 Nov 27;376(9755):1861-8.

5. Bravata DM, McDonald KM, Smith WM, Rydzak C, Szeto H, Buckeridge DL, et al. Systematic review: surveillance systems for early detection of bioterrorism-related diseases. Ann Intern Med. 2004 Jun 1;140(11):910-22. 
6. Henning KJ. What is syndromic surveillance? MMWR Morb Mortal Wkly Rep. 2004 Sep 24;53 Suppl:5-11.

7. Mitchell M, Hedt-Gauthier BL, Msellemu D, Nkaka M, Lesh N. Using electronic technology to improve clinical care - results from a before-after cluster trial to evaluate assessment and classification of sick children according to Integrated Management of Childhood Illness (IMCl) protocol in Tanzania. BMC Med Inform Decis Mak. 2012 Dec 31;13:95.

8. Aanensen DM, Huntley DM, Feil EJ, al-Own F, Spratt BG EpiCollect: linking smartphones to web applications for epidemiology, ecology and community data collection. PLoS One. 2009;4(9):e6968.

9. Haskew J, Kenyi V, William J, Alum R, Puri A, Mostafa Y, et al Use of mobile information technology during planning, implementation and evaluation of a polio campaign in South Sudan. PLoS One. 2015 Aug 7;10(8):e0135362.
10. Sheikhali SA, Abdallat M, Mabdalla S, Qaseer BA, Khorma R, Malik M, et al. Design and implementation of a national public health surveillance system in Jordan. Int J Med Inform. 2016 Apr;88:58-61.

11. World Health Organization. International Classification of Diseases (ICD) (http://www.who.int/classifications/icd/en/, accessed 3 May 2-017).

12. A project document for public health surveillance in Jordan. Amman: Ministry of Health; 2016:1-39.

13. Jordan public health surveillance. Amman: Ministry of Health; 2015: 1-27.

14. Open Data Kit 2014 (ODK) [website] (http://www.opendatakit.org, accessed 3 May 2017). 